\title{
A new research paradigm for pediatric radiology — can we climb the pyramid?
}

\author{
George S. Bisset III
}

Received: 4 April 2013 / Revised: 16 July 2013 / Accepted: 10 October 2013

(C) Springer-Verlag Berlin Heidelberg 2013

Although this is truly an exciting time in our remarkable subspecialty of pediatric radiology, it is also a time for introspection. Under the ever-increasing pressure to do more clinical work, are we doomed to neglect the importance of advancing our field? And if we recognize the importance of meaningful investigation, are we in a good position to overcome the many obstacles to fostering high-quality research in pediatric radiology? I hope the answer to this last question is "yes," but I will pose some challenges for each of us to consider.

Research can be simple or complex, but for many the mention of the word creates angst. I frequently hear, "I can't do research," or "I'm not sure how to start." And I would like to tell you that resources ... and protected research time ... and praise ... and the Society for Pediatric Radiology ... and a supportive work environment would solve this problem, but I have learned over the years that these don't work without more basic ingredients to make research prosper.

If we examine the "evidence pyramid," which provides a framework for discovery, we can measure how pediatric radiology stacks up (Fig. 1) [1]. As one moves up the pyramid the amount of available literature decreases, but the literature that is there increases in its clinical relevance. David Hume, a well-known philosopher, once said, "A wise man proportions his belief to the evidence" [2]. Yet when we look at many of the publications in Pediatric Radiology, unfortunately, we hover closer to the bottom half of the pyramid. And we are not entirely to blame for this conundrum. Radiology is the only medical discipline that is defined by the imaging

G. S. Bisset III $(\bowtie)$

Department of Radiology, Texas Children's Hospital, Baylor College of Medicine, 6701 Fannin St., Ste. 470, Houston, TX 77030, USA

e-mail: gsbisset@texaschildrens.org approach to a medical problem rather than by an organ system or disease process [3]. This creates some unique issues, and perhaps contributes to our tendency to publish descriptive research, rather than working at the top of the pyramid. Although these retrospective reviews, technical feasibility studies, and case reports have value, their scientific validity is variable.

But the absence of ascension to the top may be a failing of our training as much as the plight of our specialty. One of the things I have discovered over the years is that our training in the performance of quality research is deficient. This lack of training has created a dearth of mentors in the pediatric research arena. We are left with a vicious cycle-without the mentors and appropriate training we can't effectively build research infrastructure, and so the problems are perpetuated. It is easy to throw in the towel. Other than a select few, our training programs don't offer substantive teaching in statistics,

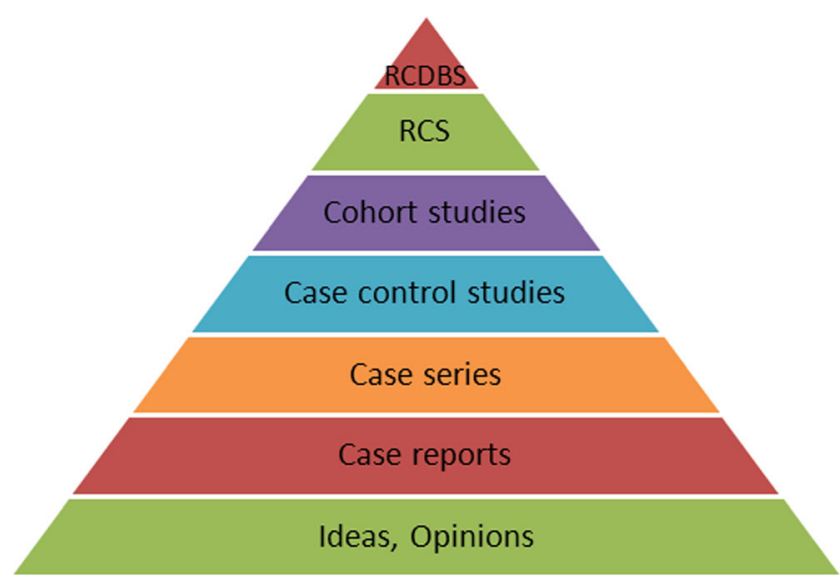

Fig. 1 Evidence hierarchy pyramid. $R C D B S$ randomized controlled double-blind studies, $R C S$ randomized controlled studies 
study design, comparative effectiveness, and evidence-based outcomes [4].

As our technology evolves we have a unique opportunity to design outcomes studies based on the state-of-the-art tools we have at our disposal. A key theme of the 2010 Institute of Medicine Roundtable discussion was "drawing clinical research closer to practice" and going beyond efficacy (whether an intervention works in an idealized environment) to effectiveness (how an intervention works in daily practice) [5]. In the era of accountable care organizations, where expedited diagnosis and treatment are at a premium, we must demonstrate to our clinical colleagues how cost-effective approaches are dependent upon timely imaging. We need to get past the bias that is inherent in many of our observational studies. The key is to provide scientific evidence that what we do is critical. If we can answer Cochrane's three questions: (1) Can it work (efficacy)? (2) Will it work (effectiveness)? and (3) Is it worth it (balance of costs, safety, risk)? for all research studies, we will be on our way to answering the challenge in clinical effectiveness research. No subspecialty has contributed more to positive change in health care over the last 25 years than radiology. We must sustain this legacy.

\section{References}

1. DeVoto E, Kramer BS (2005) Evidence-based approach to oncology. In: Chang A (ed) Oncology: an evidence-based approach. Springer, New York

2. Hume D (1748) An enquiry concerning human understanding. eBooks@adelaide (http://ebooks.adelaide.edu.au/h/hume/david/ h92e/) Accessed March 22, 2013

3. Gooding CA, Donnelly LF, Jaramillo D (1998) Pediatric radiology research: anticipating the millennium. Radiology 206:579-581

4. Welty LJ, Carter RE, Finkelstein DM et al (2013) Strategies for developing biostatistics resources in an academic health center. Acad Med 88:454-460

5. Institute of Medicine (US) roundtable on value and science-driven health care (2010) In: Olsen LA, McGinnis JM (eds) Redesigning the clinical effectiveness research paradigm: innovation and practicebased approaches: workshop summary. National Academies Press, Washington, DC 